\title{
The Relevance of Web Mapping Infrastructures in a Web Portal for Desktop and Mobile Devices: A Case Study
}

\author{
Kai Behncke', Manfred Ehlers ${ }^{2}$ \\ ${ }^{1}$ Creativista Solutions, Osnabrueck, Germany \\ ${ }^{2}$ Institute for Geoinformatics and Remote Sensing, University of Osnabrueck, Osnabrueck, Germany \\ Email: behncke@creativista-solutions.de,mehlers@igf.uni-osnabrueck.de
}

Received October 11, 2012; revised November 13, 2012; accepted December 10, 2012

\begin{abstract}
There exists a lack of detailed empirical studies to assess the relevance of WebMapping applications. Despite this fact, it is quite common to note that importance and influence of WebMapping applications have increased over the last years. This paper presents the result of an empirical study to analyze the importance of a Desktop-WebMapping application for a gastronomic web 2.0 portal for the city of Osnabrück. An exploratory focus is to evaluate how often geospatial information (in a broader information context) from this web portal is used and how important the WebMapping applications are for the users of the web portal. Furthermore, it is evaluated which WebMapping functions (e.g. routing, queries, printing) are of relevance to the users and what the order of importance is for the provided functions. To-date, just a few mobile WebMapping applications for handheld devices exist. Consequently, for OsnaGo we developed a mobile WebMapping component that can be used with mobile phones, PDAs and other handheld devices to access the web portal (http://www.osnago-mobil.de). Development and user based evaluation is presented in this paper.
\end{abstract}

Keywords: WebMapping; WebGIS; Open Source; Mobile GIS

\section{Introduction}

The number and relevance of WebMapping applications have increased in the last years [1-4]. Dickmann claims, that "since the mid-1990s the number of maps designed and distributed on the World Wide Web has increased dramatically. From an original scientific niche, this new technology has grown to almost universal application in many practical contexts" [5]. Chang and Tsou write: "The development of Internet Mapping and Web GIS applications is a global trend and becomes one of the major innovative tools for education and public affairs in the 21st century" [1]. A reason for this is the existence of different Mapping-APIs and freely available data (e.g. Google Maps, Yahoo!, OpenStreetMap). It is nowadays far easier than in the years before to create "mappingmashups" (i.e. a combination of different maps and services in a new application). In this regard the term "WebMapping 2.0" is often used [4,6,7]. In general, for these frequently delimited applications no specific "geoinformatics-knowledge" is needed [4,8,9]. Parallel to the development of WebMapping applications, the relevance of Open Source software has increased. PULSIFER et al. note: "Currently, open source software has become increasingly prominent in the Web mapping domain” [7]. Open Source WebMapping projects like
MapFish, Mapbender and especially OpenLayers have been developed with highly dynamic and integrated functionality and are used in a large number of projects $[2,10,11]$. "Regardless of how web mapping software is licensed or distributed, it is clear that the variety and functionality of available tools has dramatically increased in recent years" [7]. Within the context, WACHOWICZ et al. [12] stated: "Nowadays there is a lack of detailed usability tests for web mapping applications" and presented one of the rare studies on the usability of WebMapping applications (another one is by [13]). NEWMAN et al. [14] emphasize: "As more 'voluntary citizen sensors' adopt new spatial Web 2.0 technology (...), we must better understand (...) the usability of web mapping applications (...)”. They continue: "However, as more web mapping applications are developed, more attention must be given to their usability, user satisfaction, required tasks, data quality, and applicability related to each purpose and audience they are being built so support". Finally they conclude: "research is needed to address the new challenges $(\cdots)$ web mapping applications pose for GI Science” [14]. Currently, no empirical research or case studies are known that analyze the general relevance of WebMapping or WebGIS applications in the web or in the context of a web portal. Furthermore, no thorough study exists that evaluates the functionalities 
for WebMapping applications that are seen as eminently important. The questions that need to be asked are multifold: Are desktop WebMapping applications really as useful as is often claimed by Geoinformatics professionals? Is it not possible that web portals integrate WebMapping applications even though there are rarely used or required? And if they are used at all, to which degree? And which functions are seen as especially relevant? These questions form the basis for a Ph.D. thesis from which we will present some results in the following sections. In addition, little empirical research has been done on mobile WebMapping applications, meaning applications that run on handheld devices like PDAs, smartphones or mobile phones. The main reason for this is that hardly any mobile WebMapping applications exist. A rare example for a mobile solution is OpenLayers $[15,16]$ One factor for the lack of mobile WebMapping applications is that the mobile web is still quite "new" and the lack of standards for the different browsers impedes a speedy development. "The mobile web historically has been so horrendous to deal with, that the only way to create a compelling experience was to go native" [17]. The rendering of the source code for the different browsers is difficult [18]. FIRTMAN notes: "All mobile devices come with one preinstalled mobile browser, and very few of them can be upgraded or uninstalled" [19]. The only solution to create an application that is independent from the different mobile operating systems is to develop a server-oriented web application. "The mobile web is the only platform that is available and works across all mobile devices" [20]. In the above mentioned Ph.D. dissertation a prototype of a mobile WebMapping solution has been developed. One part of it was concerned with the evaluation of the role that the individual components play in a web portal. An excerpt of the achieved results is presented here.

\section{Methods}

We designed and developed a gastronomic web portal application for the city of Osnabrück (Germany). It was named "OsnaGo" [21] and is based on PHP, JavaScript/ AJAX, HTML, CSS, SQL (PostgreSQL) components. A comprehensive description of the portal can be found in [11]. Well-known functionalities from different gastronomic web portals (e.g. qype.de, yelp.de, restaurantkritik.de, kneipensuche.com, gastronomix.de) were integrated into OsnaGo through a strength-weakness analysis. In addition, other functions were added that do not exist in these portals. The OsnaGo portal has been designed and implemented with exclusive use of Open Source software [22].

OsnaGo displays complex information of the gastronomic facilities (e.g. contact data, opening hours, menus or details of available facilities). The caterers can publish news and advertisement. Visitors can use different query options (search by name or by different attributes) to find gastronomic objects and rate them with text and point ratings at the scale of 1 (low) to 10 (high). Based on these point ratings a comprehensive ranking is created. Besides this, a calendar for events and special offers exist. The portal integrates also an extensive list of WebMapping applications for desktop PCs ([23] see also Figure 1) which are based on MapFish, MapServer, PostgreSQL, PostGIS, and pgRouting.

The locations of the gastronomic facilities are visualized using OpenStreetMap data. Moreover, it is possible to create individual routes (and to download them as gpx-files), to search objects, to print out maps and to get mouse-click information for specific objects. Furthermore, a mobile WebMapping client is integrated into the system (http://www.osnago-mobil.de). The mobile WebMapping client is based on XHTML-MP, Javascript/ AJAX, MapServer, PHP/MapScript, CSS, pgRouting and

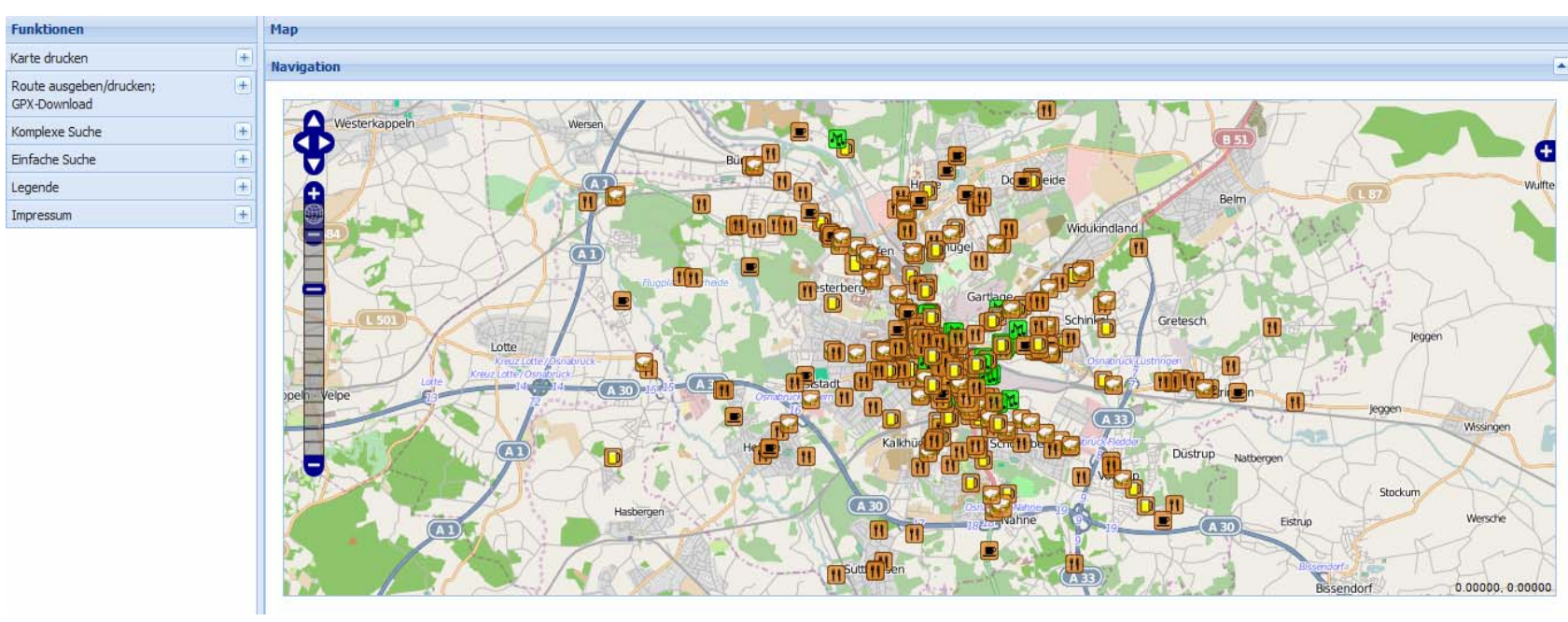

Figure 1. Layout of OsnaGo.de. 
PostgreSQL/PostGIS. The mobile WebMapping solution offers the following functions (see also Figure 2):

- Navigation, zooming;

- Activation and deactivation of layers;

- Choosing location/visualizing gastronomic objects;

- Getting information about the gastronomic facilities (e.g. contact data, opening hours, details of the equipment, rating results);

- Filtering objects (e.g. visualized are facilities which are open at a specific time);

- Routing.

The source code of the OsnaGo-portal with all its components can be downloaded in the imprint of OsnaGo [24].

With an open online survey that mainly focussed on the desktop client we examined the relevance of the WebMapping applications for the portal users. Part of the survey that was offered at the WebMapping client was to find out which of the functions were seen as highly important. Although an online survey offers many advantages over analogue questionnaires (see, for example [25]), their main problem is that it is nearly impossible to get a truly representative result [26]. Nevertheless, such an online survey is generally ruled adequate to evaluate web portals and its functionalities [25,27].

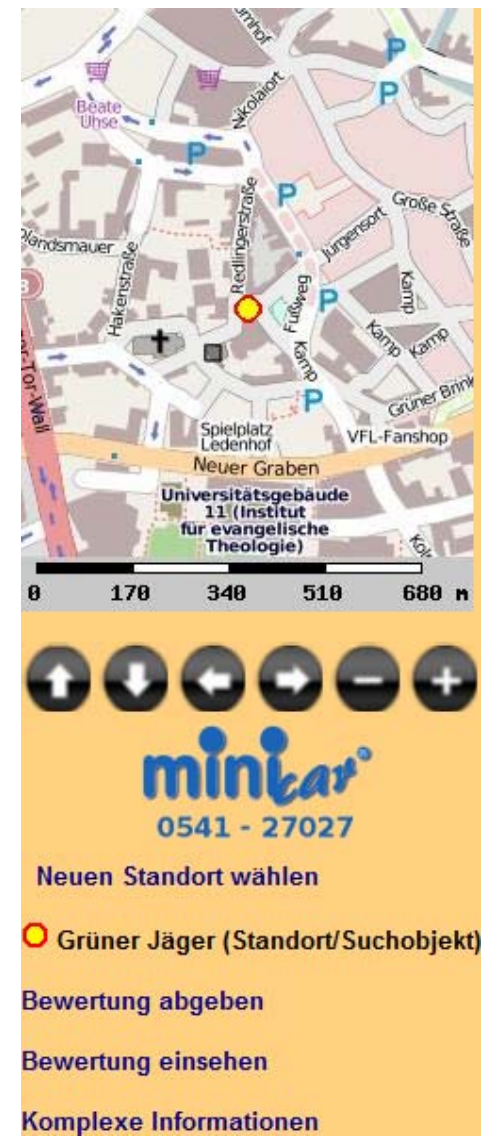

Figure 2. Layout of OsnaGo-mobil.de.
The online questionnaire was open between August 1, 2010 and October 15, 2010 at the main page of http://www.osnago.de. In addition to that, the survey was promoted in different newspapers. For the participants vouchers for gastronomic facilities were raffled. Filling out the questionnaire took about 12 - 15 minutes. The participants were visitors of the OsnaGo portal and its components during the time of the survey.

\section{Evaluation of the Survey}

In total, 159 online questionnaires were filled out; however, not all questions were answered by all participants. These questions received a "null" value and were not taken into account. Therefore, the basic number ("nvalue") was different for different questions. The answers were evaluated with "PASW Statistics" (formerly "SPSS"). Descriptive statistical methods were applied. Due to limited space in this article, only extracts of these results are published. All results can be found in [22].

It is evident that the access to rating values for gastronomic facilities is the most important factor. In $25.5 \%$ of the cases this was the reason for using OsnaGo. Getting information about a specific gastronomic object (22.1\%) and the search for specific facilities (21.8\%) also had high values. Only $8.4 \%$ of the users wanted to use one of the WebMapping applications (www.osnago-karte.de, www.osnago-mobil.de) and its specific functionalities like routing or GPX download (Figure 3).

Figure 4 shows the relevance of the WebMapping component (desktop) for the users. In general the colours in Figures 4-6 mean: red = very unimportant, orange = unimportant, yellow $=$ neutral, lime green $=$ important, dark green $=$ very important.

$16.6 \%$ of the survey participants classify this component as "very important" and $34.5 \%$ classify it as "important". Only $19.5 \%$ of the respondents say that the WebMapping application is "very unimportant/unimportant” ( $\mathrm{n}=84$ for this question). Figure 5 emphasizes that the most important functions in the Desktop-WebMapping application are the presentation of information after mouse click on an object, the different search options, the routing functionality and the printout of a map ( $\mathrm{n}$ varies for this analysis, because the questions were not answered equally). The gastronomic facilities could be queried by name (e.g. "give me all information for pub X") or by the services provided (e.g. "show me a pub with live-football on TV and specific prices for students").

The most important functions of the mobile WebMapping application for the participants of the study are information about opening hours and general information about the gastronomic facilities (not visualized here). For $34.2 \%$ the dynamic navigation map is "very important", 


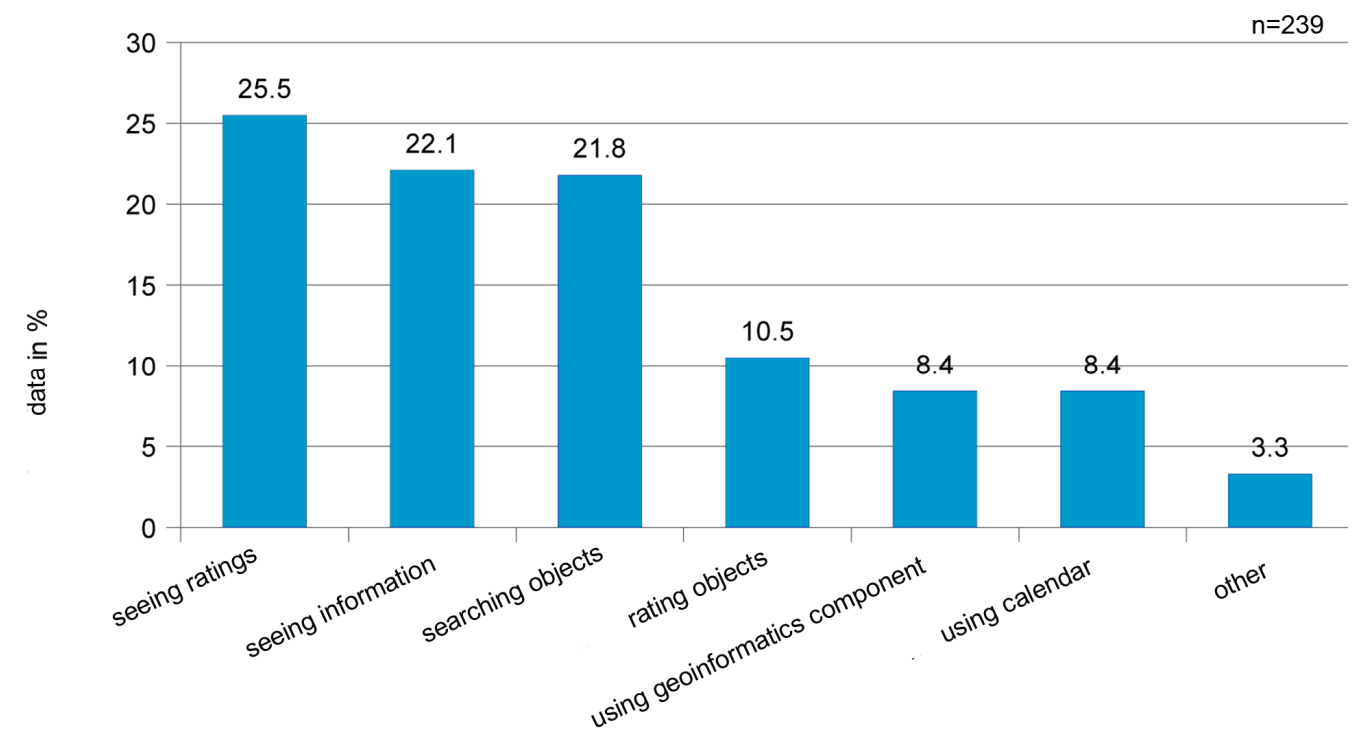

Figure 3. Reasons to use the web portal www.osnago.de.

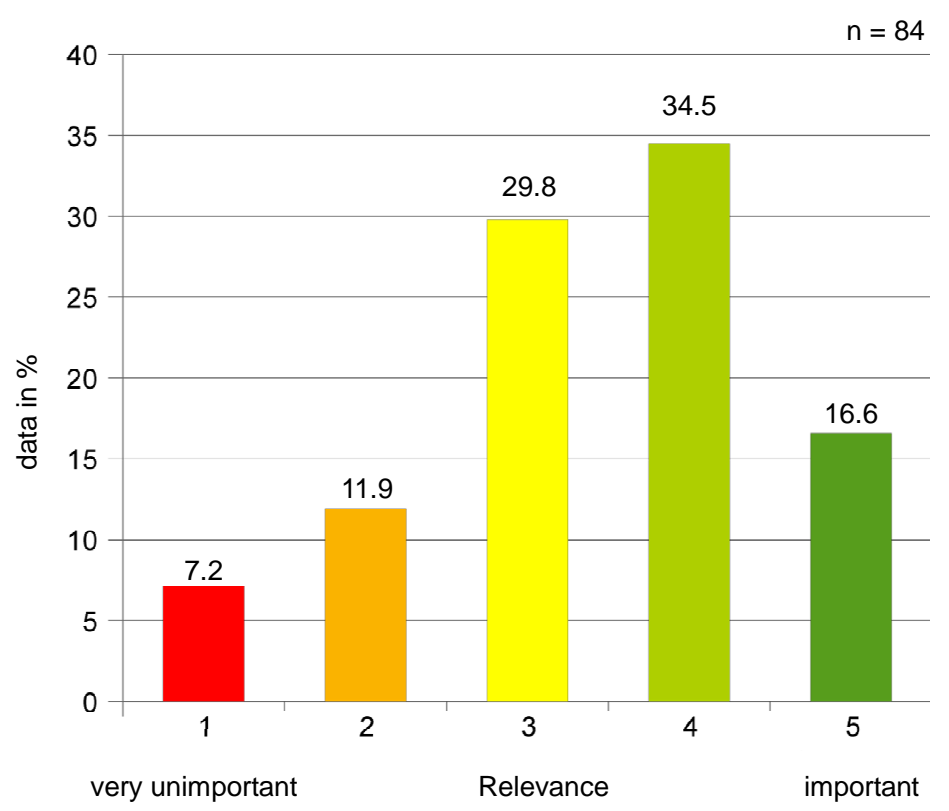

Figure 4. Relevance of the WebMapping application (desktop).

so is the routing function (33.8\%). Only one function of the mobile client seems to be "very unimportant": "Download of a route as a GPX file" (41.6\%).

As the questionnaire was published as an "open" questionnaire without registration of the users, the rationality of the answers can't be guaranteed but is supposed, as the participants got some benefits (commercial voucherbooks for restaurants and pubs of osnabrueck).

\section{Discussion}

The presented results of an empirical case study about the use and relevance of (mobile) WebMapping applications proves, that WebMapping applications are a rele- vant component of the web portal and are classified as important by the participants of the survey. Our study results on the relevance and importance of WebMapping applications confirm the statements quoted in the literature. It has to be noted that WebMapping applications do not "play a leading role" in the portal but have an important complementary character. Besides the results of the survey, the number of web-requests provides significant hints. Between August 1, 2010 and January 24, 2011 the portal osnago.de was visited by 14,139 users with a total number of 152,985 different requests (analyzed by Google Analytics). The average time of a visit is $6 \mathrm{~min}$ utes and 10 seconds. During their visit, 1602 users 
Search for an object in the map by name $(n=88)$

Search for an object in the map by attribute $(n=87)$

Presentation of information after mouse click on object $(n=91)$

Routingpresetation (Visualization in map and presentation of the description) $(n=91)$

Download of a route as gpx-file $(n=91)$

Printout of a map $(n=87)$

Printout of a routing dexcription $(n=81)$

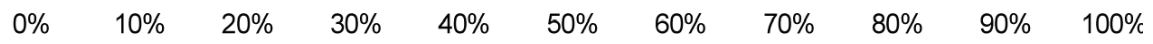

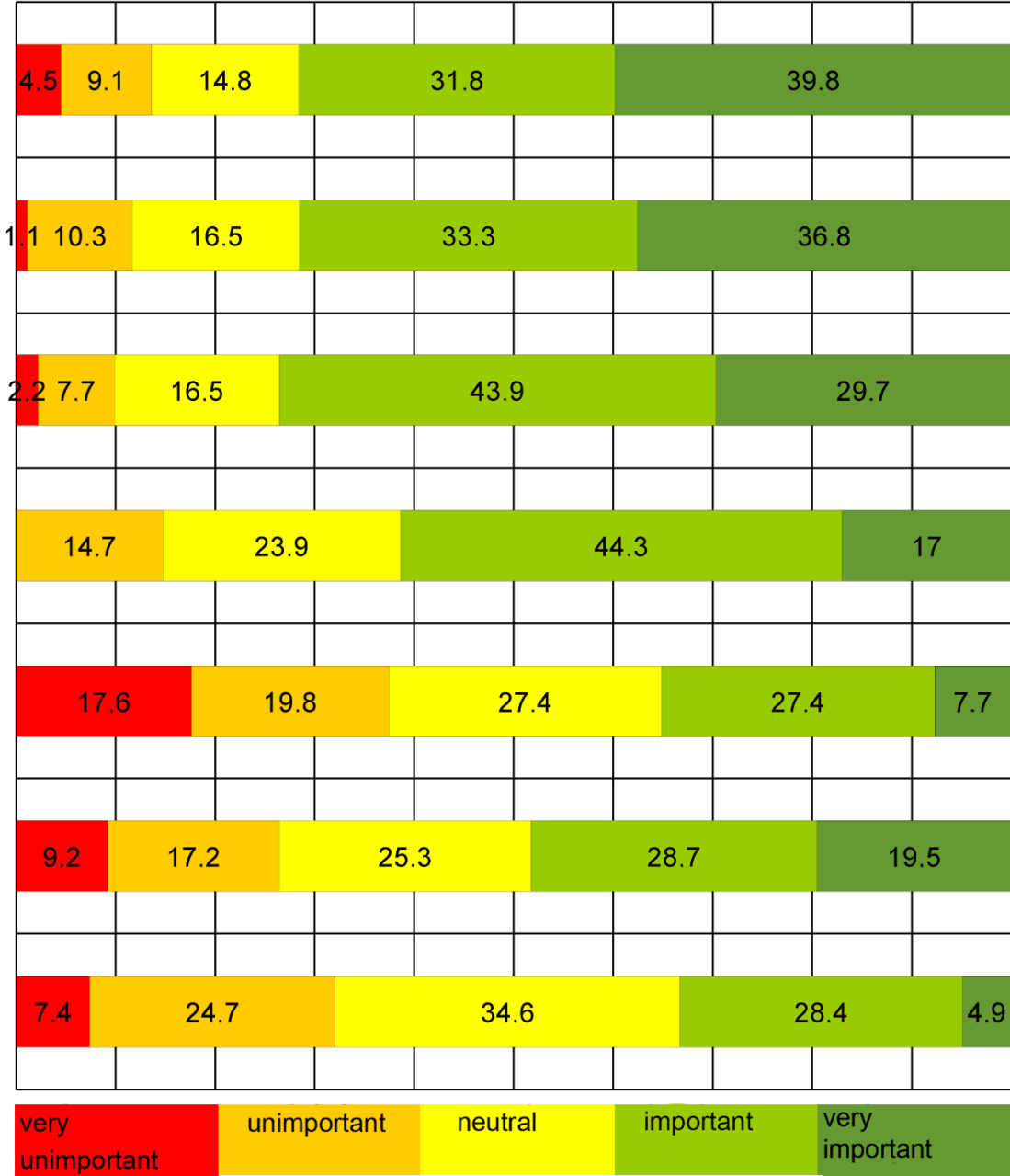

Figure 5. Relevance of functionalities of the WebMapping application (desktop).

clicked on the desktop WebMapping component (average using time 1:25 minutes) and the mobile WebMapping component was visited by 938 users.

The purpose of a WebMapping application is to present spatial information and to support user orientationno more and no less. The user wants to know how he or she can get to restaurant $\mathrm{X}$ or to pub $\mathrm{Y}$. If this spatial information is transmitted to the web site visitor, the purpose of the portal is achieved. It should also be noted that Osnabrueck is not a large city (about 140,000 inhabitants). Many gastronomic facilities are therefore quite well-known for Osnabrueck citizens. Other information or functions are requested more often due to con tent changes (e.g. news of the caterers, events, special prices, ratings). Consequently, the fact that the WebMapping solutions have "just" a supplementary character is of little surprise. In principle, the provision of spatial information can play an important role if a customer wants to visit an unknown or new gastronomic facility.
We agree especially with DICKINGER et al. [28] and FITZKE und GREVE [29] who claim that geoinformation is particularly suitable to structure, connect, and organize general information (see also [9]). The important advantage for geodata is the fact that they can be visualized in form of a web map. A web map facilitates the clear and easy-to-understand presentation of objects and their associated attributes. With this, it is very easy for the user to comprehend the information if it is made available via its location. The importance of such a provision of information is supported by the results of our study (see Figure 5): $73.6 \%$ of all survey participants agree that getting information about an object by mouse click is "important" or "very important" thus emphasizing the significance of a WebMapping component in a web portal.

\section{Conclusion}

The empirical case study (open online survey) proves 


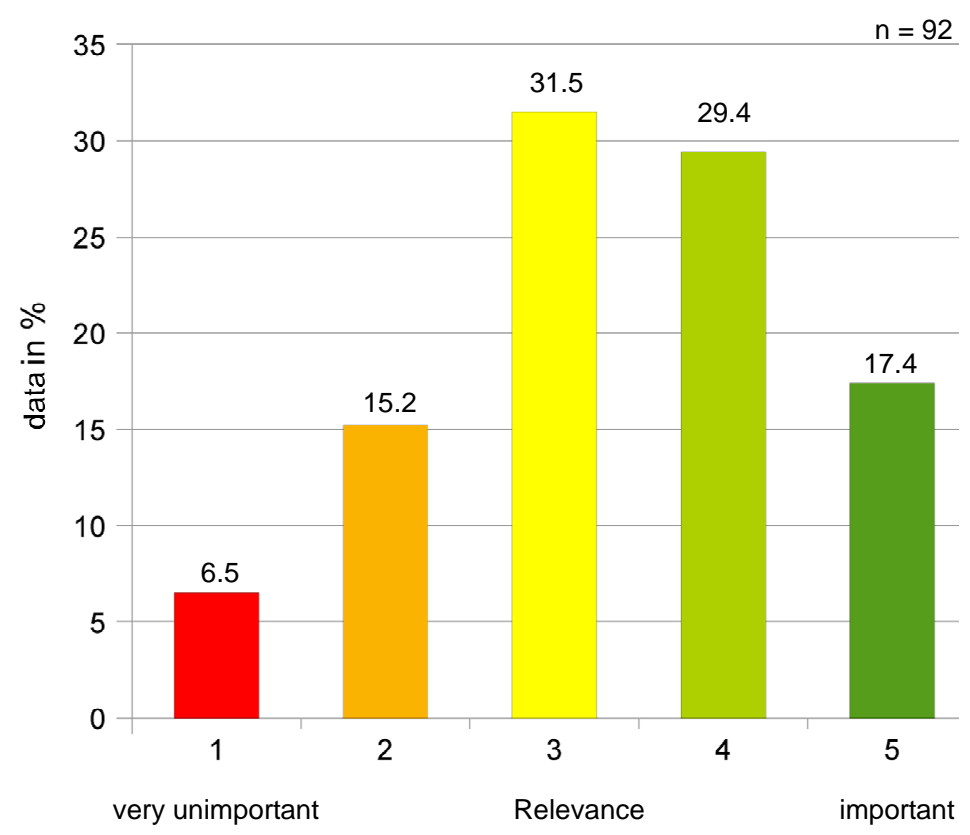

Figure 6. Relevance of the mobile WebMapping application.

that WebMapping applications (mobile and desktop application) are essentially supplemental information components but have a high relevance in a web portal. Besides that, functionalities are named that are very important for Desktop-WebMapping applications (presentation of information after mouse click on an object in the map, different query options, routing, printout of maps for a desktop WebMapping application, dynamic navigation map, routing for a mobile WebMapping application). To evaluate the results, it has to be noted that large differences between web portals and WebMapping applications exist. These differences concern functionalities, contents, and target groups. Results of our study cannot be generalized, but they show an important empirically proven tendency.

\section{REFERENCES}

[1] H. K.-C. Chang and M.-H. Tsou, "New Approaches for Integrating GIS layers and Remote Sensing Imagery for Online Mapping Services,” In: M. P. Peterson, Eds., International Perspectives on Maps and the Internet, Springer, Berlin, 2008, pp. 73-87.

[2] A. Christl, “Open Source: Trends auf der Fossgis,” GIS Business, Vol. 3, 2009, pp. 46-47.

[3] E. Simonné-Dombóvári, M. Schmidt and G. Gartner, "Mapapplications in the Web," HMD: Practise of Economyinformatics, Vol. 47, No. 276, 2010, pp. 59-67.

[4] K. Hoffmann, "Usergenerated Maps and Cartographic Communication in the Web 2.0," Cartographic News, Vol. 61, No. 2, 2011, pp. 72-78.

[5] F. Dickmann, "Effectiveness and Efficiency of Tourism Maps in the World Wide Web and their Potential for Mo- bile Map Service,” In: L. Meng, A. Zipf and T. Reichenbacher, Eds., Map-Based Mobile Services. Theories, Methods and Implementations, Springer, Berlin etc., 2005, pp. 43-53.

[6] M. Haklay, A. Singleton and C. Parker, "Web Mapping 2.0: The Neogeography of the GeoWeb," Geography Compass, Vol. 2, No. 6, 2008, pp. 2011-2039. doi:10.1111/j.1749-8198.2008.00167.x

[7] P. L. Pulsifer, A. Hayes, J.-P. Fiset and F. D. R. Taylor, "An Open Source Development Framework in Support of Cartographic Integration,” In: M. P. Peterson, Ed., International Perspectives on Maps and the Internet, Springer, Berlin etc., 2008, pp. 165-185

[8] M. Soutschek, "Usage of Geoweb-Technologies in Tourism," HMD: Practice of Economy Informatics, Vol. 47, No. 276, 2010, pp. 77-87.

[9] M. Jansen and T. Adams, "OpenLayers, Web Development with Dynamic Maps,” Open Source Press, München, 2010.

[10] C. Baudson and A. Christl, "Eine Typisierung: OpenLayers, Mapbender und MapFish,” In: FOSSGIS, Ed., Proceedings FOSSGIS-Conference for Free and Open Source Software for Geoinformatics, Osnabrück, 2-5 March 2010, pp. 30-36.

[11] K. Behncke, "Gastronom Guide with Open Source Software and Free Geodata,” GIS Science, Vol. 23, No. 1, 2010, pp. 22-25.

[12] M. Wachowicz, L. Cui, W. Vullings and J. Bulens, "The Effects of Web Mapping Applications on User Satisfaction: An Empirical Study,” In: M. P. Peterson, Ed., International Perspectives on Maps and the Internet, Springer, Berlin etc., 2008, pp. 397-415.

[13] A.-M. Nivala, S. Brewster and L. T. Sarjakowski, "Usability Evaluation of Web Mapping Sites," The Cartographic Journal, Vol. 45, No. 2, 2008, pp. 129-138. 


\section{doi:10.1179/174327708X305120}

[14] G. Newman, D. Zimmermann, A. Crall, M. Laituri, J. Graham and L. Stapel, "User-Friendly Web Mapping: Lessons from a Citizen Science Website,” International Journal of Geographical Information Science, Vol. 24, No. 12, 2010, pp. 1851-1869. doi:10.1080/13658816.2010.490532

[15] http://openlayers.org/blog/2011/02/25/mobile-sprint-day-five/

[16] http://www.terrestris.de/2011/02/28/openlayers-mobile-c ode-sprint-in-lausanne-schweiz

[17] B. Fling, “Mobile Design and Development,” O’Reilly, Beijing, 2009.

[18] S. Christmann, R. Voigts and S. Hagenhoff, "Websiteoptimation for the Mobile Web," HMD: Practise of Economyguidance, Vol. 48, No. 277, 2011, pp. 109-117.

[19] M. Firtman, "Programming the Mobile Web,” O’Reilly, Beijing, 2010.

[20] F. Angerer, "Mobile Services for the Free Time," In: R. Egger and M. Jooss, Eds., mTourism. Mobile Services in Tourism, Gabler, Wiesbaden, 2010, pp. 45-58.

[21] http://www.osnago.de

[22] K. Behncke, "Case Study to the Relevance of Webmapping-Applications within a Webportal-An Empiric Research of an Open Source Portal for the City of Osna- brueck,” Ph.D. Thesis, University of Osnabrueck, Fachbereich Mathematik/Informatik, 2011.

[23] http://www.osnago-karte.de

[24] http://www.osnago.de/osnago_sourcecode.zip

[25] S. Fühles-Urbach, "Online-Research in the Web-Overview of Methods,” In: K. Scherfer, Ed., Webscience-An Introduction, LIT, Berlin, 2010, pp. 195-209.

[26] M. Maurer and O. Jandura, "Some Critical Remarks to Representativity and Validity of Online-Questionnaires," In: N. Jackob, H. Schoen and T. Zerback, Eds., SocialResearch in the Internet. Methods and Practice of OnlineResearch, VS, Wiesbaden, 2009, pp. 61-73. doi:10.1007/978-3-531-91791-7_4

[27] J. Bortz and N. Döring, "Researchmethods for Social Scientists,” Springer, Berlin, 2009.

[28] A. Dickinger, C. Drimmel and A. Scharl, "GeoWebApplications in Tourism and Freetime,” In: A. Back, N. Gronau and K. Tochtermann, Eds., Web 2.0 in Economy Practise. Basics, Case Studies and Trends to the Use of Social Software, München, 2009, pp. 137-146.

[29] J. Fitzke and K. Greve, "Free or for Free? Usergenerated Geoinformation between Freedom and Free of Charge," In: J. Strobl, T. Blaschke and G. Griesebner, Eds., Applied Geoinformatics 2010. Contribution to the 22, AGITSymposium Salzburg, Heidelberg, 2010, pp. 732-741. 